\title{
(A) I) (1) \\ COMPREHENSIVE EVALUATION OF MODIFICATION LEVEL ASSESSMENT IN Sr-MODIFIED ALUMINIUM ALLOYS
}

\author{
Annalisa Fortini, Lucia Lattanzi, Mattia Merlin, and Gian Luca Garagnani \\ Department of Engineering (DE), University of Ferrara, Ferrara, Italy
}

Copyright (C) 2017 American Foundry Society

https://doi.org/10.1007/s40962-017-0202-3

\begin{abstract}
One way to improve the mechanical properties of Al-Si alloys is to add chemical modifiers that affect the microstructure of the cast components. Small amounts of $\mathrm{Sr}$ cause the modification of the eutectic Si particles from a coarse plate-like morphology into a fine fibrous one. This study sets out to analyse the effects of chemical modification on an $\mathrm{Al}-7 \% \mathrm{Si}-0.3 \% \mathrm{Mg}$ foundry alloy treated with $\mathrm{Sr}$, ranging from 62 to 820 ppm. Assessment of modification level was evaluated by both thermal analysis technique and

numerical methods proposed in the literature have been considered in an attempt to understand their effectiveness. The correlation between thermal analysis results and geometrical parameters of eutectic Si particles highlighted the impact of microstructural homogeneity on modification-level evaluation. In addition, the presence of $\mathrm{Ca}$ in $\mathrm{Sr}$ based intermetallics has been further investigated by means of scanning electron microscopy combined with energy-dispersive $X$-ray spectroscopy.
\end{abstract} quantitative microstructural investigations. Up to now, little attention has been paid to the role played by microstructural characteristics in evaluating the modification level, which is commonly performed by comparison with standard images. In the present investigation,
Keywords: thermal analysis, chemical modification, silicon particle image analysis, intermetallic compounds

\section{Introduction}

Al-Si alloys represent the predominant alloys used for light metal structural components in automotive and aircraft applications because of their good castability, low cost and high strength to weight ratio. Chemical composition and solidification parameters determine alloy microstructure and thus the mechanical properties of the as-cast parts. To improve fracture toughness and yield strength of such alloys, T6 heat treatment is an essential step of the production process.

An important factor which affects the fracture behaviour and the ductility of these alloys is the morphology of eutectic Si particles. Transformation of the microstructure is performed by modification treatment, which converts eutectic Si from coarse plate-like particles into fine fibrous ones. With respect to modification, this can be achieved through a rapid solidification rate (quench modification) or by adding specific elements of groups I and II of the periodic table and lanthanides (chemical modification).
Chemical modification of Al-Si alloys by means of trace additions of $\mathrm{Sr}, \mathrm{Na}, \mathrm{Sb}, \mathrm{Ca}$ and $\mathrm{Ba}$ elements is a wellknown melt treatment which yields a significant increase in mechanical properties, especially in terms of ductility. ${ }^{1-3}$ In permanent mould casting processes, $\mathrm{Sr}$ is the most frequently used modifier agent because of its good modification rate and low fading effect. The influence of $\mathrm{Sr}$ additions on mechanical properties of $\mathrm{Al}-\mathrm{Si}$ alloys has been extensively investigated. ${ }^{4-7}$ In addition, it has been observed that $\mathrm{Sr}$ which exceeds a certain amount has detrimental effects on mechanical properties, and hence proper levels of $\mathrm{Sr}$ are crucial. ${ }^{3}$ Some authors have reported that the Sr level required to adequately modify the microstructure ranges from 100 to $200 \mathrm{ppm}$, considering that the modification of the eutectic phase depends on the combination of $\mathrm{Si}$ content, cooling rate and alloying elements. ${ }^{8,9}$

The issue of Si modification can be addressed by thermal analysis (TA) investigations, and to date, online controls are of pivotal importance in the foundry industry to

Published online: 31 December 2017 
evaluate the degree of modification of the eutectic microstructure prior to casting and to optimise $\mathrm{Sr}$ content in the alloy. ${ }^{10}$ Thermal analysis has gained an increasing importance over the last decades among the different techniques employed for quality assessment. Originally established as an application tool for the control of carbon equivalent in cast iron production, today TA represents a rapid online non-destructive and quantitative technique, used in both ferrous and non-ferrous fields, to evaluate the quality of liquid metal before casting. ${ }^{8}$ Thermal analysis is cheaper and easy to use in comparison with other thermoanalytical techniques, such as differential thermal analysis (DTA), differential scanning calorimetry (DSC) and thermogravimetric analysis (TGA). ${ }^{3,8}$ Furthermore, TA offers clear advantages over common metallographic control techniques; these are costly and time-consuming and require casting trials, preparation of metallographic specimens and detailed microstructural analyses. In thermal analysis tests, molten alloy is poured into a cup with a thermocouple placed in its centre to record temperature evolution during solidification. Solidification parameters, derived from the cooling curve and its first derivative, can thus be related to a variety of treatments for different alloys, i.e. grain refinement and Si modification level in an aluminium alloy, and inoculation and graphite spheroidisation in cast iron. TA has been extensively employed in the field of aluminium foundry for quality assessments and solidification studies. ${ }^{8,11-21}$ The effectiveness of modification treatment is commonly established via TA through the calculation of eutectic growth temperature differences between modified and unmodified alloys. ${ }^{1,2,22,23}$ However, to correlate modification level to TA results, quantitative metallographic investigations must be performed. Conventionally, the degree of modification is estimated by comparing micrographs to standard charts provided by the American Foundry Society (AFS). ${ }^{19}$ These charts include six modification levels (MLs) - or classes-based on the shape and dimensions of eutectic Si particles: unmodified structures fall into class 1, partially modified into classes 2-4 and fully modified into classes 5-6. The global ML of a sample is calculated by Eqn. 1 as:

$$
\begin{aligned}
\mathrm{ML}= & (1 \cdot a \%)+(2 \cdot b \%)+(3 \cdot c \%)+(4 \cdot d \%) \\
& +(5 \cdot e \%)+(6 \cdot f \%)
\end{aligned}
$$

Eqn. 1

where $1-6$ are the modification classes and $a \%-f \%$ are the corresponding percentages. As the structures shown in the AFS charts do not always resemble those of the experimental samples, this approach fails, to a certain extent, to provide an objective comparison between standard and actual micrographs. To overcome this issue, many authors have tried to relate the ML to the geometrical parameters of eutectic $\mathrm{Si}$ particles. ${ }^{1,2,24,25}$ Djurdjevic et al. ${ }^{22}$ proposed an online quantitative method to evaluate the modification level in Al-Si alloys. An image analysis system was used to assess the modification in a 319-aluminium melt modified through the addition of $\mathrm{Sr}$, using $\mathrm{Al}-10 \% \mathrm{Sr}$ master alloy, in an amount ranging from 8 to $96 \mathrm{ppm}$. The median values of geometrical characteristics of $\mathrm{Si}$ (length, width, equivalent diameter, area and aspect ratio) were considered in order to evaluate the relative ML by comparison with the AFS charts. The results indicate a reasonably good correlation between the ML based on perimeter measurements and $\mathrm{Sr}$ content, which, in turn, is strongly correlated to the depression of the Al-Si eutectic growth temperature. Following up the quantitative analysis of $\mathrm{ML}$, Chen et al. $^{26}$ proposed a quantifying parameter named mean shape factor of eutectic Si particles, $S^{*}$, which is essentially a mean area weighted shape factor, computed as Eqn. 2:

$S^{*}=\frac{\sum_{i=1}^{n} A_{i} \frac{2 \sqrt{\pi A_{i}}}{P_{i}}}{\sum_{i=1}^{n} A_{i}}$

Eqn. 2

where $A_{i}$ is the area of a single Si particle or plate, $P_{i}$ the corresponding perimeter and $n$ the number of the analysed particles in a single region of interest (ROI). Findings showed that $S^{*}$ has good correspondence with the AFS modification charts and provides a correct modificationlevel trend.

While considerable research has been carried out on the assessment of modification level in Al-Si alloys using TA, only two studies have attempted to address quantitative evaluation of ML by setting up a relation between geometrical parameters of $\mathrm{Si}$ particles and solidification characteristics. In this light, the purposes of the present study are: to examine the effect of increasing amounts of AlSr10 master alloy on the TA characteristic parameters of an A356 foundry alloy and to evaluate the ML, by comparing the quantitative methodologies suggested by Djurdjevic et al. ${ }^{22}$ and Chen et al. ${ }^{26}$ This paper investigates the efficacy of the reported approaches in defining ML of an A356 alloy, whose Sr contents range from 62 to $820 \mathrm{ppm}$ (0.0062-0.082 wt\%). Eutectic morphology was examined in depth by quantitative microstructural investigations, and the results were correlated to TA parameters. One of the most important findings is that TA showed a correlation between Si particle distribution and ML evaluation with numerical methods. This result was further supported by a detailed SEM-EDS investigation conducted on the Srbased intermetallic particles. Moreover, a comprehensive statistical analysis of the geometrical parameters of $\mathrm{Si}$ particles was carried out to better understand the role of $\mathrm{Sr}$ content increases. Finally, a specific study on the microstructure homogeneity highlighted the importance of Si particle distribution in ML evaluation.

\section{Experimental Procedure}

\section{Melt Preparation}

Several commercial A356 aluminium alloy ingots were melted in an electric resistance furnace. The melt was then 
transferred to a holding furnace and kept at a temperature of $750 \pm 10^{\circ} \mathrm{C}$. Subsequently, six melts were prepared with different Sr levels (from 62 to $820 \mathrm{ppm}$ ) by adding AlSr10 master alloy rods. AlTi10 master alloy rods were also added to reach the targeted $\mathrm{Ti}$ nominal content of $\sim 0.12 \mathrm{wt} \%$ in all the alloys. The chemical compositions of the investigated alloys, evaluated by an optical emission spectrometer (OES), are listed in Table 1. Finally, all the melts were degassed and dedrossed through a rotary degasser supplied with Ar inert gas. This treatment also yielded a homogeneous distribution of both modifier and grain refiner agents.

\section{Thermal Analysis}

Thermoanalytical parameters of the different alloys were evaluated by pouring the melts into a steel cup $(40 \mathrm{~mm}$ height, $47 \mathrm{~mm}$ upper diameter and $30 \mathrm{~mm}$ lower diameter) pre-heated at $300{ }^{\circ} \mathrm{C}$. To obtain reproducible and accurate results from TA, three consecutive experiments were carried out for each alloy. Cooling curves were recorded for all the samples by means of a mineral-insulated K-type thermocouple $(1.5 \mathrm{~mm}$ diameter) located in the centre of the cup, $15 \mathrm{~mm}$ from the bottom. Further protection was ensured by enclosing the thermocouple in a stainless-steel sheath. Temperature and time data were recorded at a frequency of $4 \mathrm{~Hz}$ by a data acquisition system (Pico Technology TC-08 Thermocouple Data Logger) linked to a personal computer until a temperature of $400{ }^{\circ} \mathrm{C}$ was reached during cooling after solidification. The described experimental set-up is depicted in Figure 1.

The cooling curves and their derivatives were processed by a purpose-built TA MATLAB code. Experimental data processing comprised smoothing, curve fitting and plotting the derivative curves for the determination of characteristic solidification temperatures. The cooling rate (CR) was evaluated in the liquid region just prior to the nucleation of $\alpha$-Al primary phase. Several solidification parameters of the Al-Si eutectic phase were also determined according to

Table 1. Chemical Compositions of the Investigated Alloys (wt\%)

\begin{tabular}{lllllll}
\hline Alloy (\#) & Al & Si & $\mathrm{Mg}$ & $\mathrm{Fe}$ & $\mathrm{Sr}$ & $\mathrm{Ca}$ \\
\hline 1 & Bal. & 6.85 & 0.40 & 0.091 & 0 & 0.0002 \\
2 & Bal. & 6.90 & 0.32 & 0.093 & 0.0062 & 0.0002 \\
3 & Bal. & 6.91 & 0.32 & 0.094 & 0.0095 & 0.0003 \\
4 & Bal. & 6.89 & 0.31 & 0.094 & 0.0154 & 0.0003 \\
5 & Bal. & 6.92 & 0.30 & 0.095 & 0.0187 & 0.0004 \\
6 & Bal. & 6.92 & 0.30 & 0.096 & 0.0360 & 0.0004 \\
7 & Bal. & 6.83 & 0.28 & 0.096 & 0.0820 & 0.0005 \\
\hline
\end{tabular}

Alloy \#1 represents the base alloy (untreated) the descriptions in Table 2. In particular, $\Delta T_{E}$ is calculated as the difference between $T_{G, E}$ of the base alloy and those of the alloys modified with different amounts of $\mathrm{Sr}$, and $\Delta t_{P L}$ is the time interval from $T_{\mathrm{MIN}, E}$ to the moment at which $T_{\mathrm{MIN}, E}$ is reached again after the recalescence. ${ }^{27}$

\section{Microstructural Investigations}

Samples from TA were sectioned transversely to the axis of the thermocouple and prepared using standard metallographic procedures. Quantitative image analysis (IA) was performed by means of a Leica MEF4 optical microscope equipped with Leica Application Suite LAS 3.6 image analysis software. Since the solidification process determines microstructure variability according to the different areas on the sample surface, the choice of field to be evaluated is of great importance. Therefore, the investigated area was a square of $4 \mathrm{~mm}^{2}$ chosen close to the centre of the sample surface (i.e. close to the tip of the thermocouple) and included enough $\mathrm{Si}$ particles to be representative of the entire morphology. In this regard, it has been observed that variability of geometrical features of Si particles becomes negligible when the number of ROI is greater than $15 .^{26,28}$ In the present study, a composite image made up of 36 ROI observed at a magnification of $500 \times$ was considered for each specimen, ensuring a proper representation of the eutectic microstructure. Geometrical features of eutectic Si particles were measured and statistically analysed by means of IA, and ML was assessed for all the specimens by considering both the methodology proposed by Djurdjevic et al. ${ }^{22}$ and the quantifying parameter proposed by Chen et al. ${ }^{26}$ Conforming to such approaches, the median values of the geometrical characteristics of Si particles were determined along with the $S^{*}$ values. These approaches were then compared by correlating the corresponding ML to Sr content and depression of the eutectic temperature resulting from TA. Distribution and shape of Si particles were also investigated by Zeiss EVO MA scanning electron microscope (SEM), equipped with energy-dispersive X-ray spectrometry (EDS) detector.

\section{Results and Discussion}

\section{Thermal Analysis: Solidification Parameters}

Given that $\mathrm{Sr}$ additions change the portion of the curves corresponding to the eutectic transformations, important solidification parameters related to the eutectic region and $\mathrm{CR}$ of the investigated alloys are listed in Table 3. As indicated in "Thermal Analysis" section, CRs were evaluated in the liquid region just prior to nucleation of $\alpha-\mathrm{Al}$ from the slope of the line portion in the $645-630{ }^{\circ} \mathrm{C}$ temperature interval. According to the values reported in Table 3, given that $\mathrm{CRs}$ range from 1.5 to $2.2{ }^{\circ} \mathrm{C} / \mathrm{s}$ (Table 2), the influence of the cooling rate might be assumed to be negligible. 


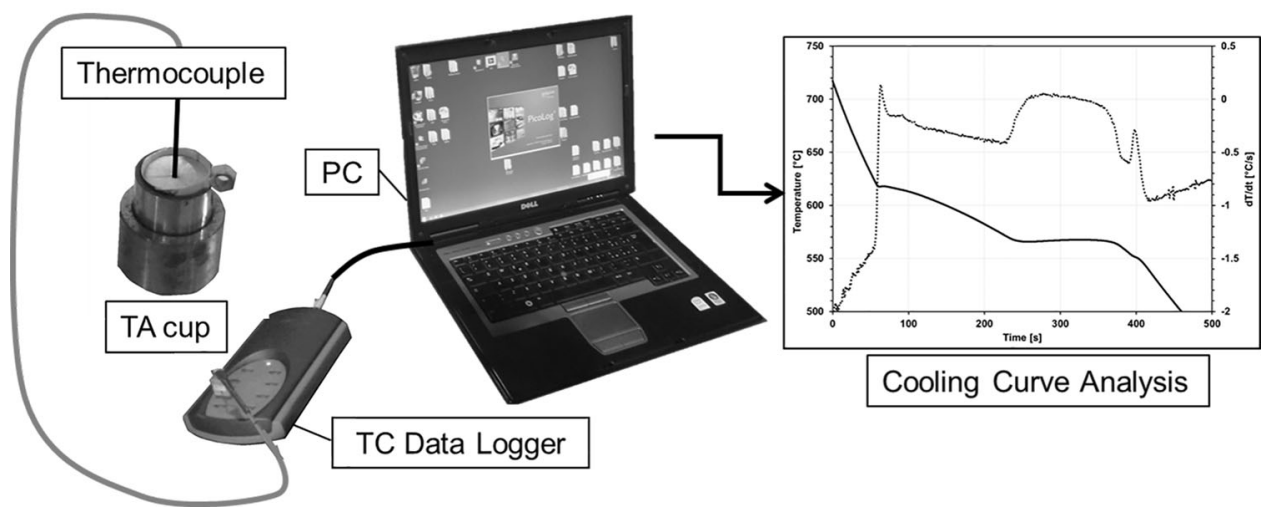

Figure 1. Thermal analysis experimental set-up.

Table 2. TA Parameters of the Al-Si Eutectic Phase Solidification

\begin{tabular}{ll}
\hline Parameter & Description \\
\hline$T_{N, E}$ & Al-Si eutectic nucleation temperature \\
$T_{\text {MIN,E }}$ & Al-Si eutectic minimum temperature \\
$T_{G, E}$ & Al-Si eutectic growth temperature \\
$\Delta T_{E}$ & Al-Si eutectic growth undercooling \\
$\Delta t_{P L}$ & Duration of the eutectic plateau \\
\hline
\end{tabular}

Table 3. Average Values of Solidification Parameters Calculated from Cooling Curves at the Eutectic Region and Cooling Rates Determined Using Cooling Curve Analysis

\begin{tabular}{|c|c|c|c|c|c|c|c|}
\hline $\begin{array}{l}\text { Alloy } \\
\text { (\#) }\end{array}$ & $\begin{array}{l}\text { Sr } \\
\text { (ppm) }\end{array}$ & $\begin{array}{l}T_{N, E} \\
\left({ }^{\circ} \mathrm{C}\right)\end{array}$ & $\begin{array}{l}T_{\mathrm{MIN}, E} \\
\left({ }^{\circ} \mathrm{C}\right)\end{array}$ & $\begin{array}{l}T_{G, E} \\
\left({ }^{\circ} \mathrm{C}\right)\end{array}$ & $\begin{array}{l}\Delta T_{E} \\
\left({ }^{\circ} \mathrm{C}\right)\end{array}$ & $\begin{array}{l}\Delta t_{P L} \\
\text { (s) }\end{array}$ & $\begin{array}{l}\mathrm{CR} \\
\left({ }^{\circ} \mathrm{C} / \mathrm{s}\right)\end{array}$ \\
\hline 1 & 0 & 574.9 & 574.3 & 574.5 & 0.0 & 14.2 & 1.7 \\
\hline 2 & 62 & 566.6 & 564.8 & 566.3 & 8.2 & 79.7 & 1.9 \\
\hline 3 & 95 & 566.9 & 565.0 & 566.1 & 8.4 & 76.2 & 1.8 \\
\hline 4 & 154 & 567.9 & 565.6 & 567.0 & 7.5 & 76.6 & 2.0 \\
\hline 5 & 187 & 567.8 & 565.5 & 567.3 & 7.1 & 104.7 & 1.5 \\
\hline 6 & 360 & 567.4 & 565.9 & 568.2 & 6.2 & 102.7 & 1.5 \\
\hline 7 & 820 & 568.4 & 567.5 & 569.9 & 4.6 & 107.9 & 1.5 \\
\hline
\end{tabular}

To study how the chemical composition affects the evolution of cooling curves, solidification parameters were analysed in conjunction with the Sr content, as depicted in Figure 2 for nucleation, minimum and growth temperatures of eutectic transformation. It is worth noting that, with respect to the unmodified alloy, $\mathrm{Sr}$ addition leads to depression of all the eutectic temperatures. $T_{N E}, T_{\mathrm{MIN}, E}$ and $T_{G, E}$ are clearly dependent on chemical composition since, from the first addition of $\mathrm{Sr}$, temperature values are lowered up to $10{ }^{\circ} \mathrm{C}$ with respect to the unmodified alloy. As can be observed in

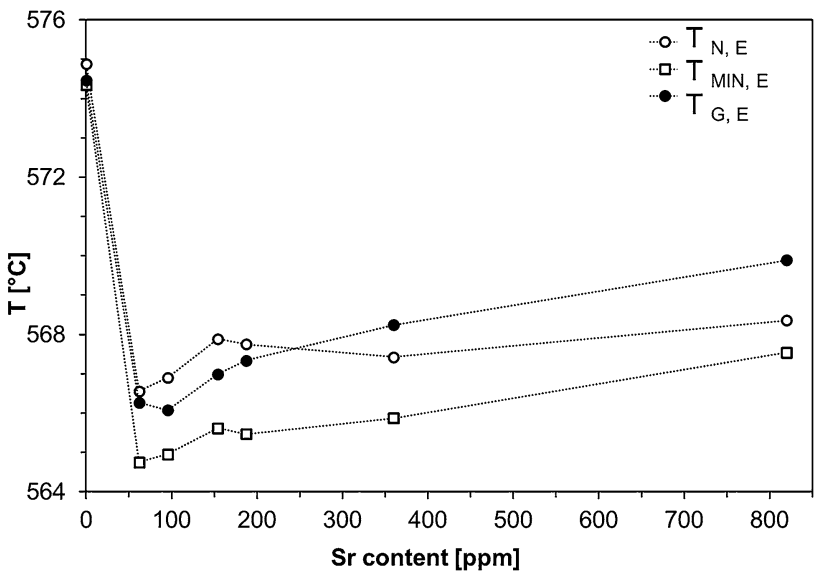

Figure 2. Evolution of eutectic temperatures versus $\mathrm{Sr}$ content.

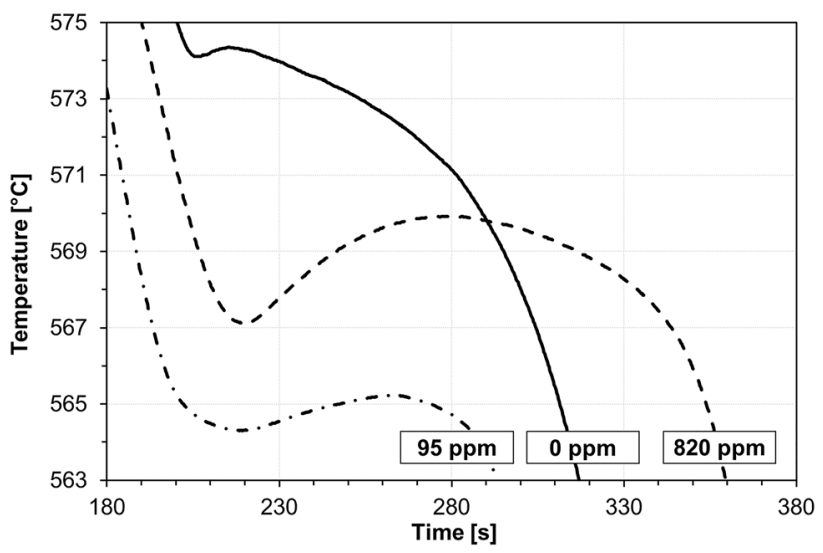

Figure 3. Cooling curves of the eutectic region for alloys with different Sr contents.

Figure 3, thermal parameters of the eutectic solidification show a substantial decrease with the addition of $95 \mathrm{ppm}$ of Sr. With further additions up to $820 \mathrm{ppm}$, the cooling curve slightly rises up of $3{ }^{\circ} \mathrm{C}$. A possible explanation for the observed trends might regard the fact that $\mathrm{Sr}$ promotes the nucleation of Si particles over growth. As a consequence, $\mathrm{Sr}$ reduces minimum temperature and growth temperature of 
eutectic Si phase. ${ }^{14,29,30}$ From a practical point of view, lower temperatures lead to a better filling in the interdendritic regions and should reduce casting defects. As shown in Figure 2, it is apparent that temperatures are shifted to lower values with $\mathrm{Sr}$ addition up to a certain content. ${ }^{14,31}$ According to the reported trends, minimum values of all temperatures are achieved when $\mathrm{Sr}$ content is in the range 62-100 ppm. Sr additions exceeding 150-200 ppm lead to data increases in proportion to the $\mathrm{Sr}$ content.

Along with eutectic temperatures, duration of the eutectic plateau $\Delta t_{P L}$ is suggested as an indicator of Si modification level. ${ }^{32}$ Figure 4 presents the evolution of $\Delta t_{P L}$ with respect to $\mathrm{Sr}$ content. As can be seen, an initial significant increase in $\Delta t_{P L}$ from $14.2 \mathrm{~s}$, for the untreated alloy, to $79.7 \mathrm{~s}$ is observed due to the addition of $62 \mathrm{ppm}$ of Sr. The trend of this time-related parameter is almost constant at about $80 \mathrm{~s}$ for $\mathrm{Sr}$ contents up to $154 \mathrm{ppm}$ and shows a significant additional increase at higher Sr levels. With further additions of modifier, the duration of the eutectic plateau remains relatively unvaried at about $110 \mathrm{~s}$.

It is widely accepted that depression of the eutectic growth temperature with respect to that of unmodified alloy, $\Delta T_{E}$, is the most widely used parameter of the cooling curve employed for the assessment of ML. ${ }^{1,2,12,26,31,33}$ By considering the evolution of $\Delta T_{E}$ as a function of the $\mathrm{Sr}$ amount (Figure 5), it is evident that the maximum values can be achieved by $\mathrm{Sr}$ levels at about $100 \mathrm{ppm}$, since $\Delta T_{E}$ is increased from 0 to $8.4{ }^{\circ} \mathrm{C}$ when the $\mathrm{Sr}$ amount is raised to $95 \mathrm{ppm}$. Further $\mathrm{Sr}$ additions of more than $200 \mathrm{ppm}$ result in a significant reduction in eutectic growth undercooling values, revealing that an excess of modifier does not provide real benefit to $\mathrm{Si}$ particle modification.

What stands out from the reported trends is that Sr additions that exceed $200 \mathrm{ppm}$ do not improve modification level of the alloy. It has been stated ${ }^{1,34-38}$ that $\mathrm{Sr}$ levels exceeding 100-150 ppm contribute to over-modification of

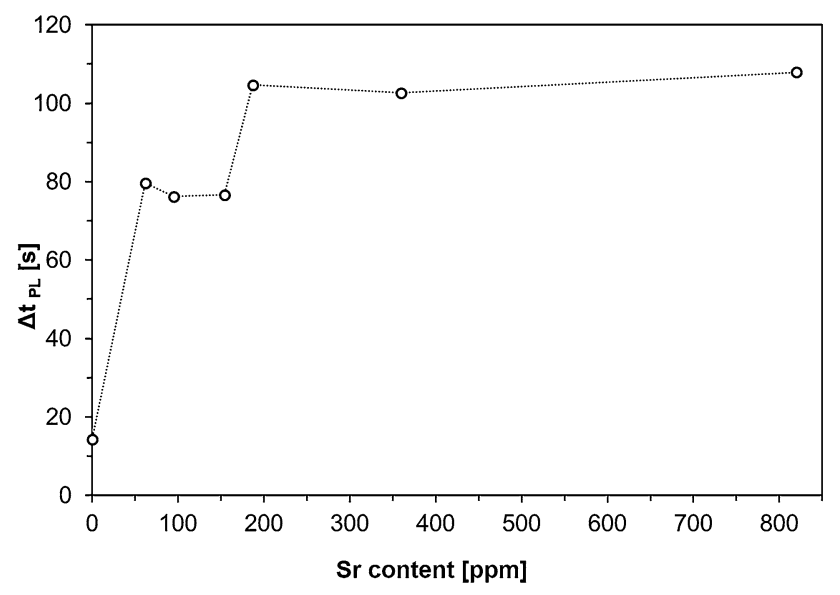

Figure 4. Evolution of the duration of the eutectic plateau versus Sr content.

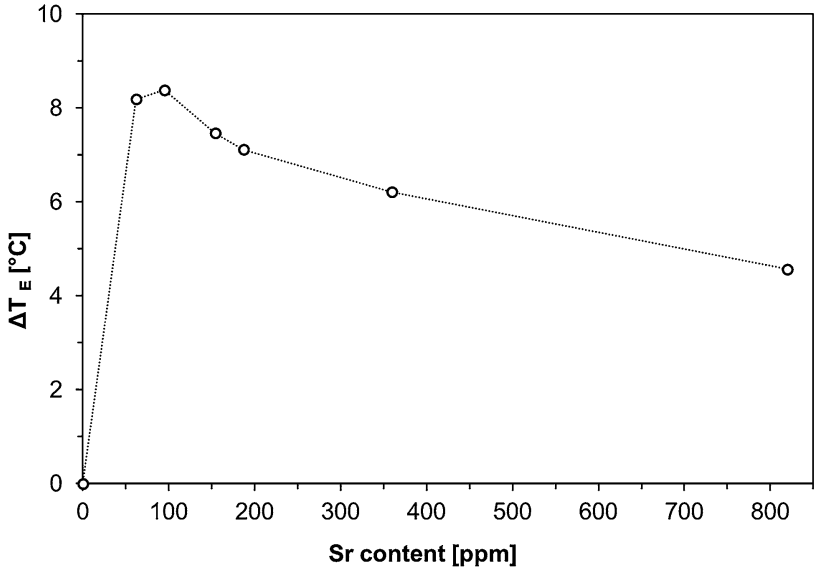

Figure 5. Evolution of eutectic undercooling versus $\mathrm{Sr}$ content.

eutectic Si particles that assume a coarse plate-like morphology (similar to the one that is typical of the as-cast condition) and the distance between them is increased. In the light of this, the sudden increase in $\Delta t_{P L}$ values for $\mathrm{Sr}$ levels higher than $200 \mathrm{ppm}$ may be related to the overmodification phenomenon which could also be responsible for the decrease in $\Delta T_{E}$. These results seem to be consistent with other researches ${ }^{35}$ which stated that over-modification is related to the segregation of Sr-based compounds in A356 alloy treated with $\mathrm{Sr}$ additions of $302 \mathrm{ppm}$. Since $\mathrm{Sr}$ is involved in the formation of intermetallic particles, it is unable to cause eutectic modification.

\section{Modification Level: Microstructural Evaluation}

It is a common knowledge that the microstructure of a typical $\mathrm{Al}-\mathrm{Si}-\mathrm{Mg}$ cast alloy is composed of a mixture of $\alpha$ $\mathrm{Al}$ dendrites surrounded by $\mathrm{Al}-\mathrm{Si}$ eutectic phase. In unmodified alloys, the Si particles form a coarse plate-like morphology which, in turn, affects the mechanical properties. This is the reason why specific amounts of $\mathrm{Sr}$ are usually added to the melt to promote the formation of finer and fibrous Si particles.

Figure 6 compares the microstructural variation in Si particle morphology for different Sr contents: 62, 154, 187, 360 and $820 \mathrm{ppm}$, respectively. It should be noted that 36 ROI captured at a magnification of $500 \times$ was merged in composite OM images, depicted in Figure 6, to analyse a proper investigation area. As can be clearly seen in Figure $6 \mathrm{a}$, modification occurs even with a low content of $\mathrm{Sr}$ (62 ppm) which promotes a reduction in the size of $\mathrm{Si}$ particles. The latter appears with fine fibrous morphology although some regions of unmodified or partially modified structures can still be appreciated (Figure 6a). Increasing $\mathrm{Sr}$ addition up to $154 \mathrm{ppm}$ (Figure 6b) results in a more homogeneously modified eutectic phase, characterised by fine fibrous eutectic $\mathrm{Si}$ particles. Further additions of modifier, as depicted in Figure 6c, d, do not improve the 

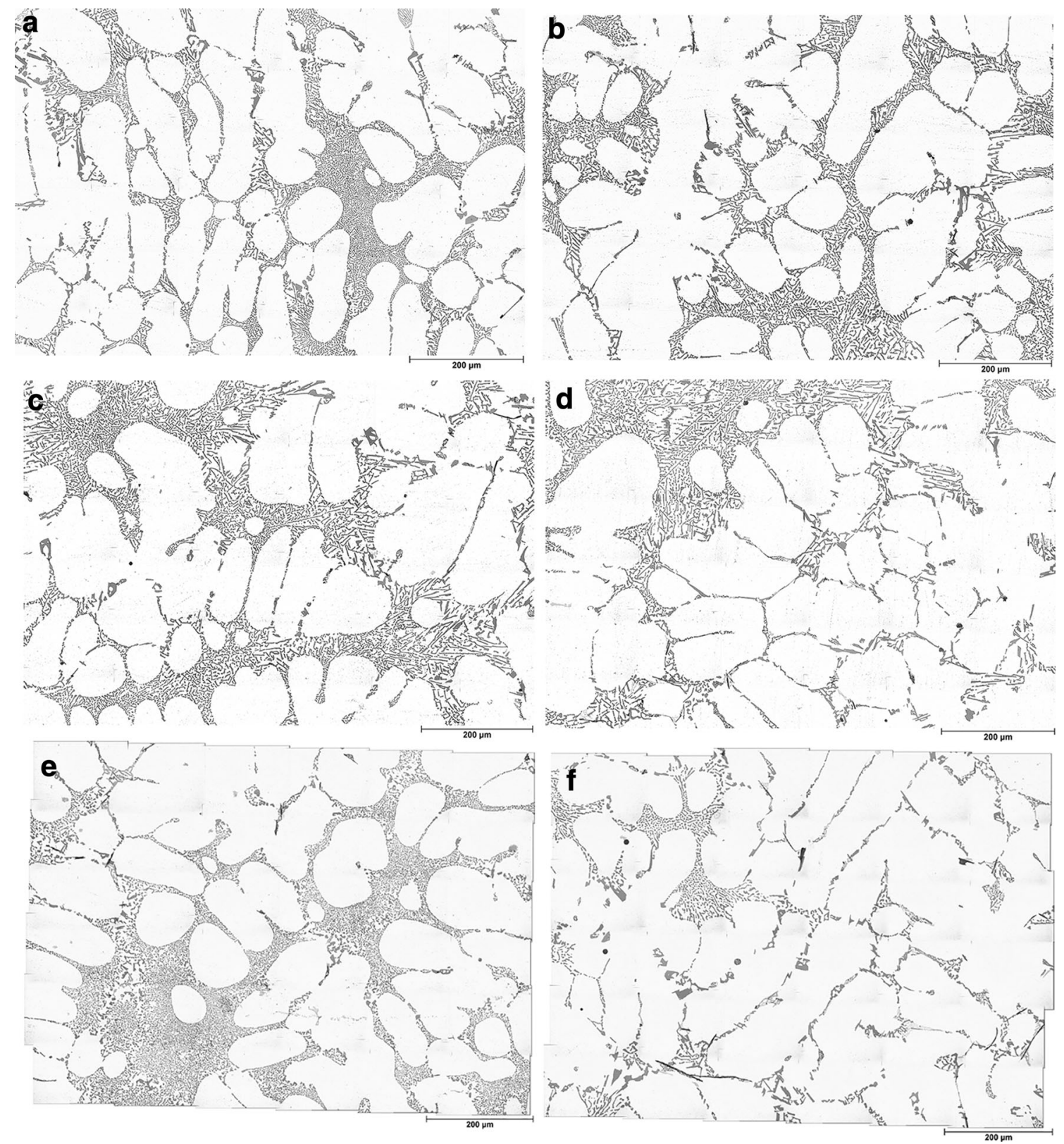

Figure 6. Effect of Sr content on eutectic Si particles: (a) $62 \mathrm{ppm}$, (b) $154 \mathrm{ppm}$, (c) $187 \mathrm{ppm}$, (d) $360 \mathrm{ppm}$, (e) and (f) $820 \mathrm{ppm}$.

morphology of the eutectic structure since areas of fine particles are accompanied by wide regions of coarse platelets. This aspect is particularly evident for the sample containing $820 \mathrm{ppm}$ of $\mathrm{Sr}$ for which both modified eutectic $\mathrm{Si}$ particles (Figure 6e) and partially modified eutectic Si particles (Figure $6 f$ ) are present. Thus, from a comparison of the optical micrographs of Figure 6, increasing the $\mathrm{Sr}$ content over a certain amount seems to affect microstructural homogeneity.

To date, there are many published studies that underline the influence of $\mathrm{Sr}$ on solidification behaviour ${ }^{4,5,14,39-42}$ and state the optimum $\mathrm{Sr}$ level to obtain a fully modified structure. ${ }^{3,10}$ However, to the knowledge of the present authors, very few studies have investigated over-modification effects on the microstructure related to the formation of Sr-based intermetallic compounds. ${ }^{1,34,35}$ According to Ref. 41, it has been observed that, at $\mathrm{Sr}$ levels greater than $300 \mathrm{ppm}$, the eutectic Si particles remain modified even when $\mathrm{Al}-\mathrm{Sr}$-Si-based compound appears in the microstructure. Such Sr content, however, might generate deleterious intermetallic compounds which reduce the amount of $\mathrm{Sr}$ in solution and are responsible for the degradation of alloy performance. ${ }^{43}$ The coarsening of $\mathrm{Si}$ particles and the segregation of Sr-based intermetallics ascertain the over-modification, ${ }^{35}$ as shown in the micrographs of Figure 6e, $\mathrm{f}$. 
With the aim of evaluating the effect of a large amount of $\mathrm{Sr}$, above $300 \mathrm{ppm}$, on the eutectic microstructure, a detailed SEM analysis of microstructural constituents was performed on specimens containing $360 \mathrm{ppm}$ of $\mathrm{Sr}$ and $820 \mathrm{ppm}$ of $\mathrm{Sr}$, respectively. The results obtained from the investigation conducted on the two modified alloys revealed the presence of a large amount of bright polyhedral particles, as reported in Figure $7 \mathrm{a}$ for the sample containing $820 \mathrm{ppm}$ of Sr. As can be seen in the backscattered electron (BSE) images of Figure 7a, light grey eutectic Si particles are found with both fine and coarse shapes, as pointed out in the optical micrograph of the over-modified sample (see Figure 6e, f), reported in this section. Strong evidence of over-modification is related to the presence of large numbers of bright polyhedral particles, located close to the larger acicular eutectic Si. The simultaneous presence of partially modified and wellmodified regions, as displayed in the low-magnification image of Figure 7a, is also evident. The SEM-EDS measurements on the particles provided the approximate atomic ratios $\mathrm{Sr}: \mathrm{Al}: \mathrm{Si}=1: 2: 2$, which fit with the stable phase $\mathrm{Al}_{2} \mathrm{Si}_{2} \mathrm{Sr}$, as reported in the EDS spectrum of Figure $7 b$.
This result is consistent with previous investigations on the formation of intermetallics in cast $\mathrm{Al}$ alloys. Samuel et al. ${ }^{44}$ studied the effects of $\mathrm{Sr}$ on the decomposition of $\mathrm{Fe}$-intermetallics in Sr-modified aluminium alloys. The metallographic investigation conducted on the Sr-treated alloys, with quantities from 300 up to $800 \mathrm{ppm}$, revealed that increasing the $\mathrm{Sr}$ content results in the precipitation of $\mathrm{Al}_{2} \mathrm{Si}_{2} \mathrm{Sr}$ compound. The authors observed that these intermetallic particles have polyhedral shape and the composition was confirmed with wavelength dispersion spectroscopic (WDS) analysis. Given that the Sr-based intermetallic particles were mostly detected attached to the $\beta-\mathrm{Al}_{5} \mathrm{FeSi}$ platelets, the authors also assumed that the $\mathrm{Si}$, rejected from the Fe-based particles, reacts with the $\mathrm{Sr}$ in the surrounding area, resulting in the formation of the Al$\mathrm{Si}-\mathrm{Sr}$ phase. Moreover, it has been hypothesised that the Sr-based compound could precipitate directly from the melt when the Sr level is sufficiently high. ${ }^{44,45}$

On the basis of the microstructural investigations reported in this section, and the cited findings of the research studies regarding both over-modification and $\mathrm{Sr}$-based intermetallics, it can be suggested that time and temperature trends (Figures 2, 4, 5) are connected to the precipitation of the $\mathrm{Al}_{2} \mathrm{Si}_{2} \mathrm{Sr}$ particles (Figure 7).

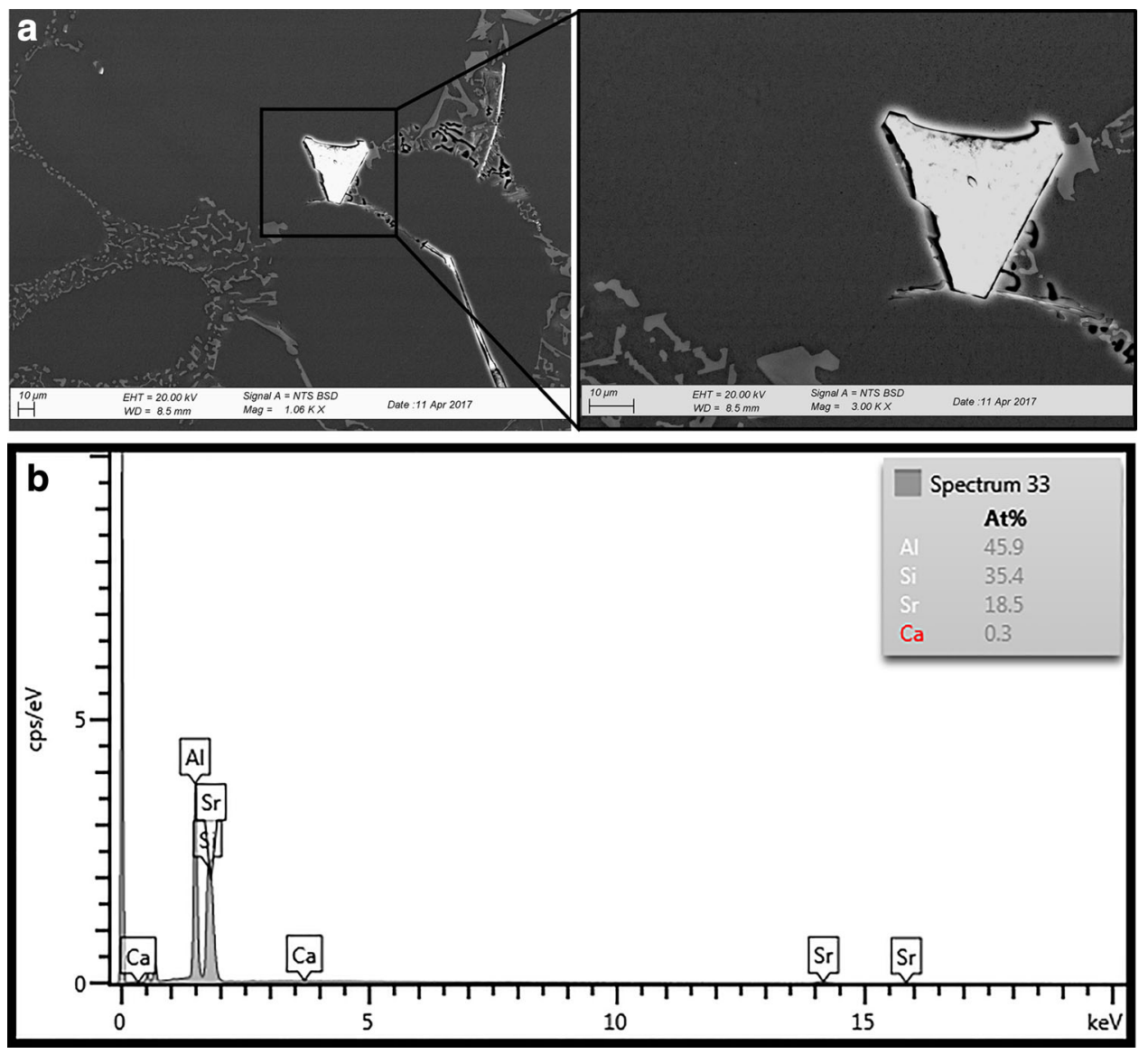

Figure 7. (a) SEM images of Sr-based intermetallic compound (low magnification and blow-up) and (b) related EDS spectrum. 
One interesting finding is that many Sr-based particles, depicted in Figure 8a, b, also present $\mathrm{Ca}$ peaks in their respective EDS spectra, as can be seen in Figure 8c, d.

To further understand and explain the presence of $\mathrm{Ca}$ in $\mathrm{Sr}-$ based intermetallic compounds, a specific investigation related to their electronic structure and thermodynamic stability has been carried out. Previous studies have established that $\mathrm{Ca}$ behaves as a modifying element in cast aluminium alloys ${ }^{46}$ as do $\mathrm{Sr}$ and $\mathrm{Na}$. It has also been found that an excessive amount of $\mathrm{Sr}$ leads to the formation of $\mathrm{Al}_{2} \mathrm{SrSi}_{2}$ or $\mathrm{AlSrSi}^{35}$ Likewise, a phenomenon akin to over-modification takes place when $\mathrm{Ca}$ content exceeds a threshold amount, and the precipitation of $\mathrm{Al}_{2} \mathrm{CaSi}_{2}$ occurs. ${ }^{47}$ Moreover, few studies have investigated the deleterious interactions which arise when both $\mathrm{Sr}$ and $\mathrm{Ca}$ are present simultaneously with the resulting reduction in modification of eutectic Si particles that become coarse and irregular. $^{46,48}$ Nakae et al. ${ }^{49}$ reported that the modifying action of $\mathrm{Sr}$ was reduced by the presence of $200 \mathrm{ppm}$ of $\mathrm{Ca}$ and completely inhibited with $600 \mathrm{ppm}$ of Ca. El-Hadad et al. $^{50}$ found that $\mathrm{Ca}$ additions greater than $50 \mathrm{ppm}$ coarsened the eutectic Si particles in a Sr-modified 319 alloy, because of the formation of $\mathrm{Al}-\mathrm{Si}-\mathrm{Ca}-\mathrm{Sr}$ compounds. The form and the chemical composition of the latter depend on the $\mathrm{Mg}$ content in the alloy. It has been suggested $^{50}$ that the chemical composition of the plate-like phase is likely to be $\mathrm{Al}_{2} \mathrm{Si}_{2}(\mathrm{Sr}, \mathrm{Ca})$, but no confirmation of these facts has been demonstrated. In the light of this evidence, it is possible that the presence of $\mathrm{Ca}$ in the EDS spectra (Figure 8c, d) of Sr-based intermetallics may be explained by considering some cross-sectional investigations related to the lattice structure of this kind of compound.

Previous studies have reported the formation of AlSiSr and AlSiCa intermetallic compounds with the same lattice structure C32. ${ }^{51}$ Moreover, it should be noted that $\mathrm{Ca}$ and $\mathrm{Sr}$ are placed directly above each other in the same group of the periodic table and thus have the same electron valence configuration, respectively, 4 and $5 \mathrm{~s}^{2}$. This is the reason why they can occupy the same lattice position in the compounds MAlSi $(\mathrm{M}=\mathrm{Ca}, \mathrm{Sr})$, despite the larger atomic mass and the larger atomic radius of $\mathrm{Sr}^{52}$ Hence, there are reasons to hypothesise that $\mathrm{Ca}$ atoms could partially replace $\mathrm{Sr}$ atoms in the electronic structure of the $\mathrm{Al}-\mathrm{Si}-\mathrm{Sr}$ intermetallic compounds, resulting in $\mathrm{Al}_{2} \mathrm{Si}_{2}(\mathrm{Sr}, \mathrm{Ca})$. In line with the suggested replacements of $\mathrm{Mg}$ by $\mathrm{Ca}^{53}$ and of $\mathrm{Si}$ by $\mathrm{Ge}^{54}$ in the $\mathrm{Al}-\mathrm{Mg}-\mathrm{Si}$ system, the presence of both $\mathrm{Ca}$ and $\mathrm{Sr}$ in the EDS spectra of the same particles (Figure 8) can be explained by the electron valence configuration which is the same for the two elements.
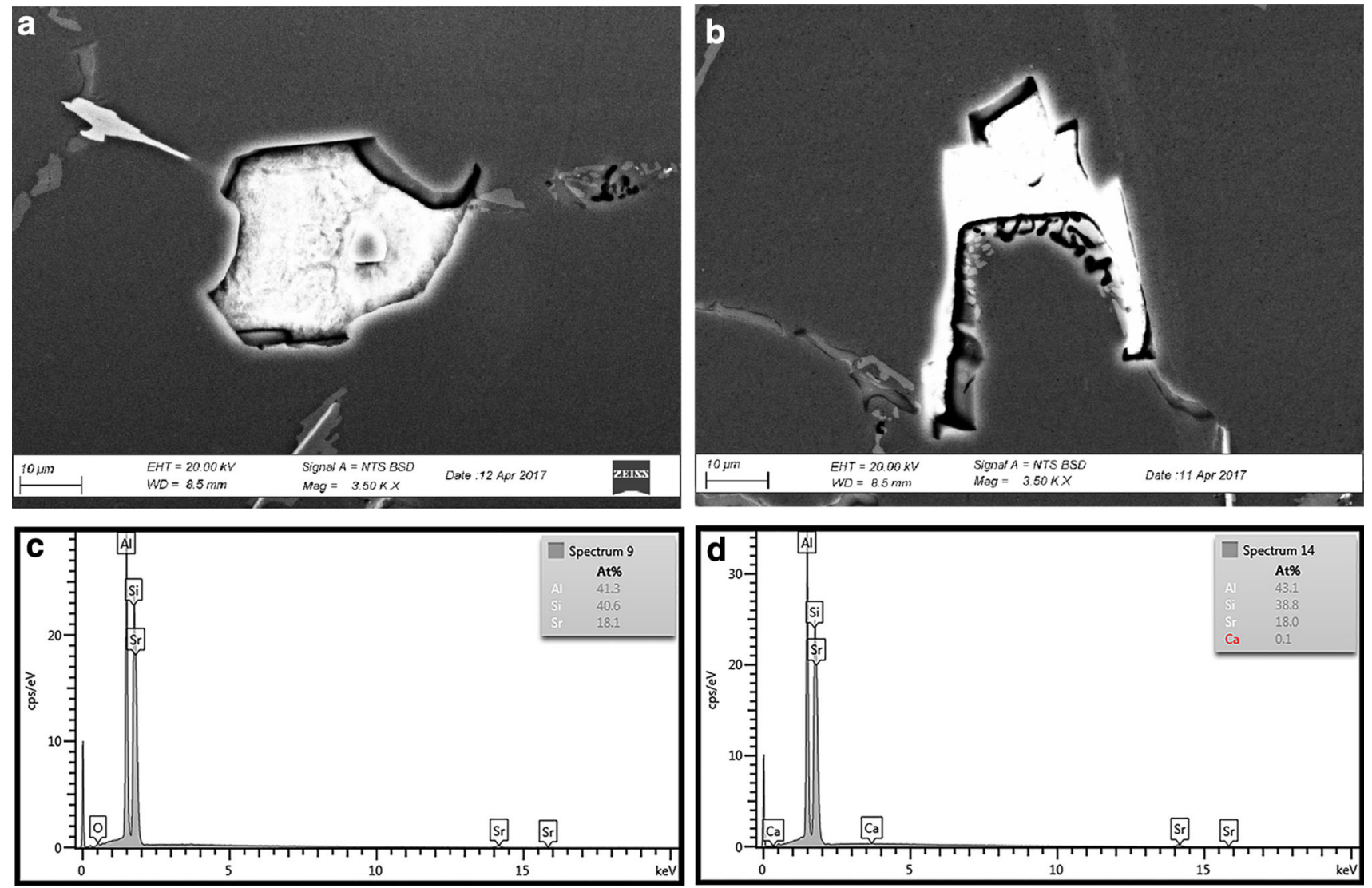

Figure 8. BSD images of Sr-based compounds (a) and (b) with related EDS spectra that show the presence of Ca (c) and (d), respectively. 

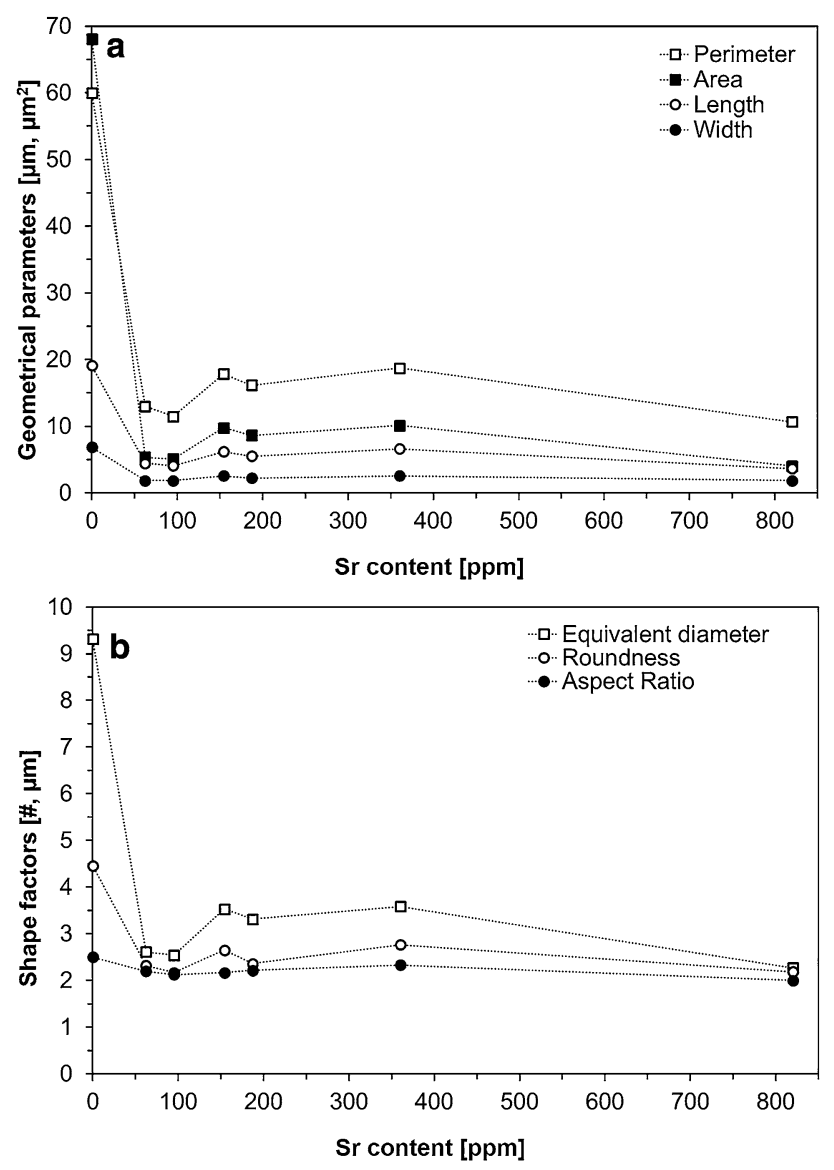

Figure 9. Median values of the Si particle characteristics as a function of the Sr content: (a) geometrical parameters and (b) shape factors.

\section{Modification Level: Quantitative Evaluation by Image Analysis Technique}

It is well known that in Al-Si alloys, eutectic Si particles in the unmodified melt appear coarse, acicular and with a polyhedral morphology. Conversely, in the presence of modifying elements, eutectic Si particles become fine and fibrous. Moreover, during solution treatment, the coarsening of the particles promotes an increase in the average particle size and in their roundness. Conversely, in as-cast condition, as for TA samples, Si particles are irregularly shaped. Thus, their characterisation must include information on geometrical parameters (e.g. length, width, area) as well as information on particle shape (e.g. shape factors). Geometrical features enable shape quantification in order to classify them in terms of shape and size. Another way to analyse particle features is based on equations and ratios of linear measurements resulting from image analyses, thus considering the so-called shape factors.

Based on the statements mentioned in "Microstructural Investigations" section, quantitative evaluations of $\mathrm{Si}$ modification level by image analysis were performed on the 36 ROI considered for each sample. The potential of

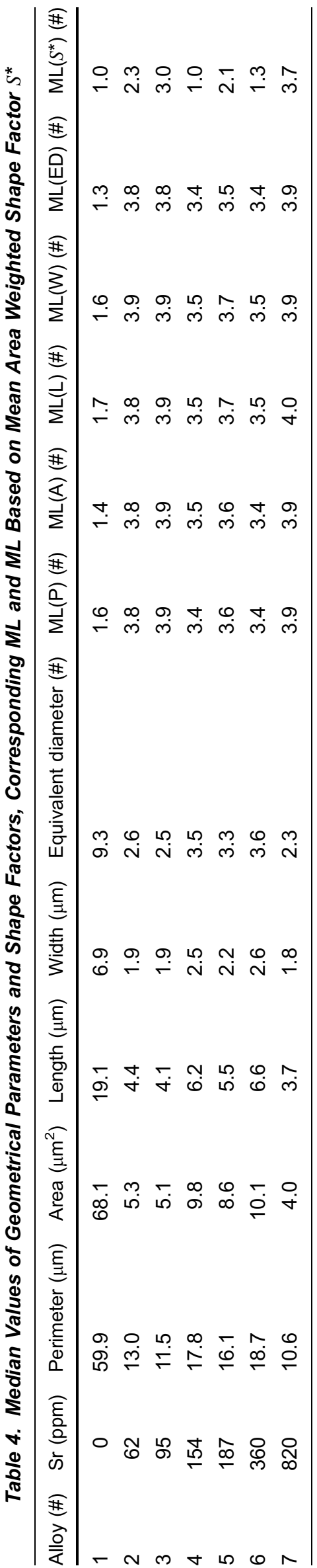


geometrical parameters in defining ML was firstly evaluated via the results of microstructural analyses, considering median values of both geometrical parameters (Figure 9a) and shape factors (Figure 9b) as a function of the $\mathrm{Sr}$ content. As can be seen from data in Figure 9a, geometrical parameters are affected by the $\mathrm{Sr}$ amount and the most sensitive ones appear to be perimeter and area. In general, all the median data show the minimum values for $\mathrm{Sr}$ level around $100 \mathrm{ppm}$ which augment with increasing additions of the modifier. The most striking result to emerge from the data is that for the alloy with $820 \mathrm{ppm}$ of $\mathrm{Sr}$, where excess Sr addition lowers the ML as suggested by Figure 5, the median values decrease with respect to the alloy with $320 \mathrm{ppm}$ of $\mathrm{Sr}$ and reach values that are comparable to those of the alloy with $90 \mathrm{ppm}$ of $\mathrm{Sr}$, a content close to the theoretical optimum. With respect to shape factors, whose evolution is depicted in Figure 9b, the equivalent diameter (i.e. the diameter of the circle with the same area as the particle) is the most sensitive. Lastly, among all the median values, no significant differences were found for the aspect ratio of the $\mathrm{Si}$ particles (i.e. the length divided by width) with increased Sr contents. This result is keeping with that of Djurdjevic et al. ${ }^{22}$ who observed an almost constant evolution of ML based on the aspect ratio parameter. Hence, the aspect ratio parameter is not a good descriptor of Si modification level and, for this reason, aspect ratio was not considered for ML evaluation in this study.

In view of these experimental findings and following the methodologies proposed by Djurdjevic et al. ${ }^{22}$ and by Chen et al., ${ }^{26}$ the assessment of ML was done as follows. Table 4 provides the median values of perimeter, area, length, width and equivalent diameter, calculated by image analyses which were considered for ML assessment. The related value of ML was calculated for each parameter by linear interpolation between actual median value and the corresponding upper limits proposed by

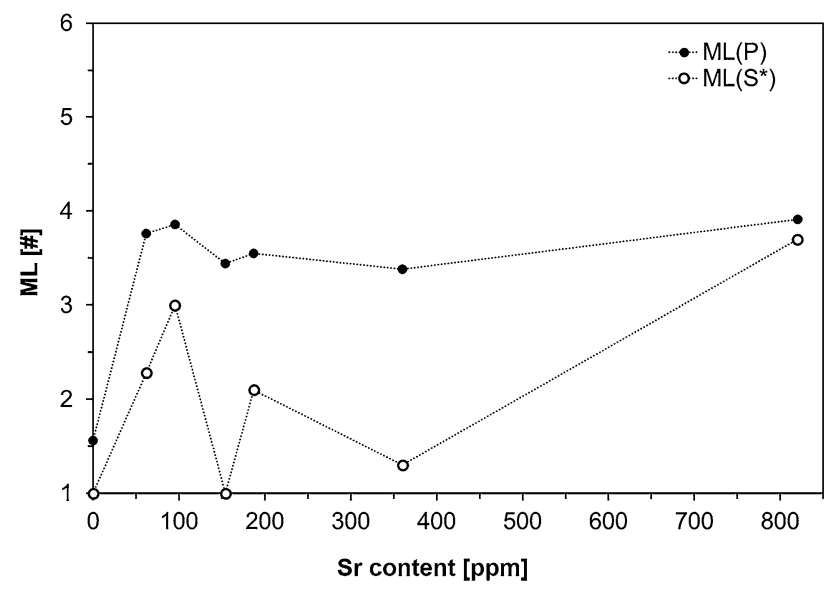

Figure 10. Evolution of ML versus Sr content arising from median values of perimeter of Si particles and from mean area weighted shape factor.
Djurdjevic et al. ${ }^{22}$ In order to assess ML with the method proposed by Chen et al., ${ }^{26}$ values of the mean area weighted shape factor $S^{*}$ were calculated according to Eqn. 2. ML was assessed by linear interpolation of $S^{*}$ values between the corresponding ranges reported by Chen et al. ${ }^{26}$ The resulting ML values are also summarised in Table 4, and the evolution of $\operatorname{ML}(P)$ and $\operatorname{ML}\left(S^{*}\right)$ as a function of $\mathrm{Sr}$ content is reported in Figure 10. It is worth highlighting that for both geometrical parameters and equivalent diameter, the modification level increases rapidly for the first $\mathrm{Sr}$ addition, reaching its maximum for a $\mathrm{Sr}$ amount of $95 \mathrm{ppm}$. With the additional increase in Sr, ML decreases and all the parameters under consideration show a similar evolution. However, in contrast to the eutectic growth undercooling evolution reported in Figure 5, the alloys with $820 \mathrm{ppm}$ of Sr show a ML similar to or superior to the one with $62 \mathrm{ppm}$ of $\mathrm{Sr}$. A possible explanation for this might be that in defining the ranges for ML evaluation, no information about the microstructure homogeneity was considered. ${ }^{55}$ In fact, fine inhomogeneously modified Si particles can lead to a ML higher than the one that could result from unmodified particles homogenously distributed. Conversely, partially modified particles within a generally well-modified Si region can determine a ML lower than the expected one. With respect to the ML arising from $S^{*}$, as reported in Figure 10, contrary to expectations, there is no evolution consistent with the Sr contents. A sudden increase in ML for $\mathrm{Sr}$ additions up to $95 \mathrm{ppm}$ can be seen, but for greater amounts, ML results in scattered data. This experimental finding suggests that assessment of ML based on $S^{*}$ does not represent an effective method.

\section{Statistical Considerations}

In the light of the ML values listed in Table 4, distribution of $\mathrm{Si}$ particles data was investigated in depth. Statistical analysis was performed by comparative boxplots. The boxplot method, first proposed by John Tukey, ${ }^{56}$ is a powerful graphical representation of results that gives an overview and a numerical summary of a data set. A detailed description of the main components of a boxplot can be found in Ferreira et al. ${ }^{57}$ Figure 11 provides the boxplots for perimeter of $\mathrm{Si}$ particles excluding the outlier data (Figure 11a) and at the same time considers data not included in the fences (Figure 11b). As can be seen from Figure 11a, all the boxplots show that the line of the median moved from the centre of the box and that the upper whisker is longer than the lower, revealing that all data sets follow an asymmetric distribution, skewed in the direction of the longer whisker. This effect is particularly evident for the unmodified alloy whose upper whisker extends up to $250 \mu \mathrm{m}$. Given that this sample contains no $\mathrm{Sr}$, the corresponding $\mathrm{Si}$ particles are coarse, with high variability of the perimeters whose median value is the highest. The difference between the third and the first 

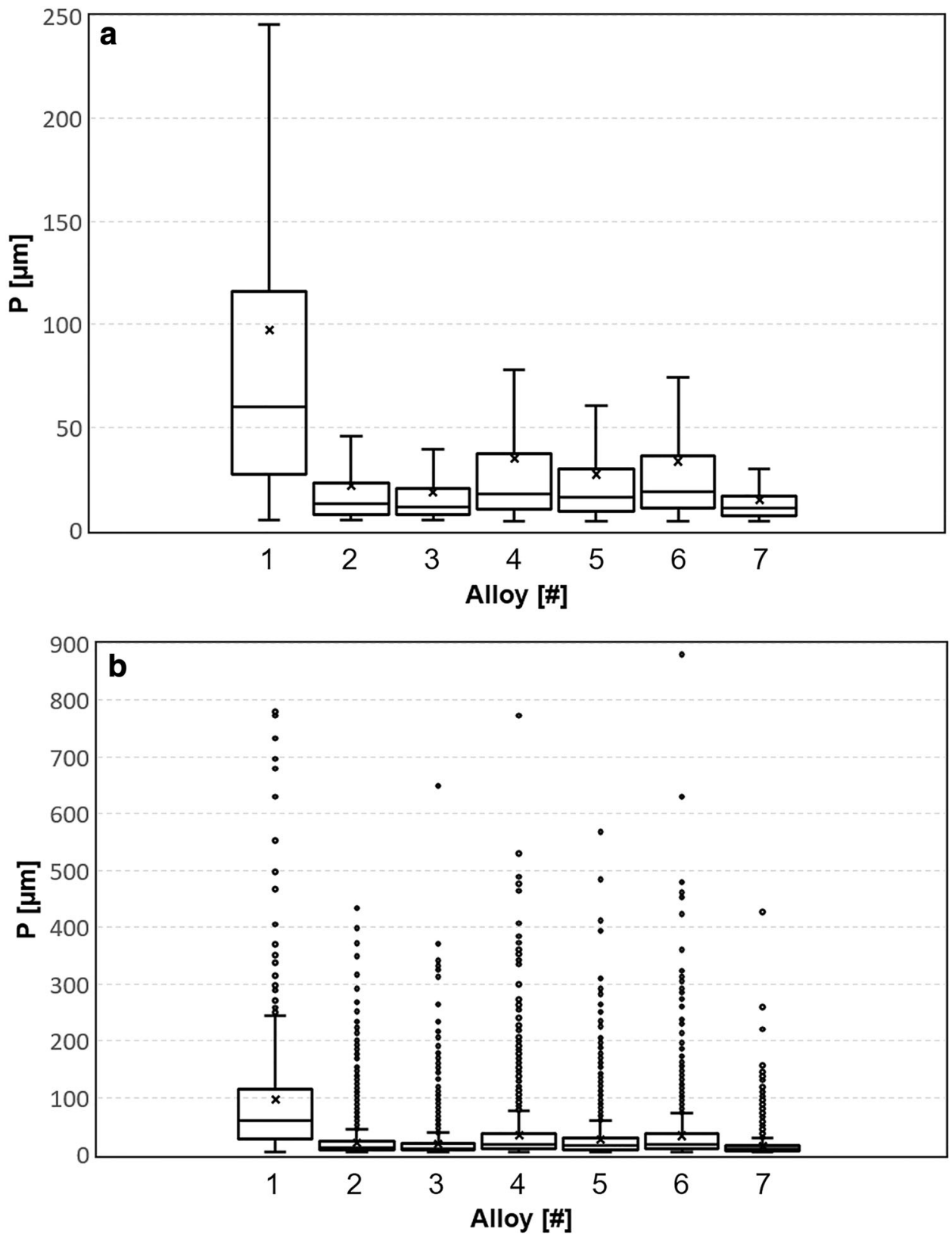

Figure 11. Boxplots for perimeter of Si particles: (a) without outliers and (b) with outliers.

quartile, referred to as interquartile range (IQR), of the unmodified alloy shows the widest range of perimeter values, and the upper position of this boxplot reveals that unmodified alloy has coarser $\mathrm{Si}$ particles in comparison with modified ones. Such evidence is also supported by the fact that median for the unmodified alloy $(59.9 \mu \mathrm{m})$ is higher or comparable to the maximum values of modified alloys. Among the latter, values for the perimeter of $\mathrm{Si}$ particles are distributed in a short range, while the contrary is found for the unmodified alloy. Furthermore, focusing on the evolution of the median values with $\mathrm{Sr}$ content, from the boxplots of Figure 11a it emerges that the lower values are associated with the alloys containing 62, 95 and $820 \mathrm{ppm}$ of Sr. This result is in accordance with the evolution of the modification level depicted in Figure 10. What is interesting, and not evident by using only the median values, is the variation of the IQR parameters with increased $\mathrm{Sr}$ contents. $\mathrm{Sr}$ additions lead to the reduction in the IQR ranges, i.e. decrease the dispersion of data, and lower their median values. Perimeter data appear less scattered for the alloys with 62 and $95 \mathrm{ppm}$ of Sr, which are the optimum $\mathrm{Sr}$ contents. Adding more $\mathrm{Sr}$ leads to an increase in IQR for the alloys with 154, 187 and 360 ppm of $\mathrm{Sr}$. 

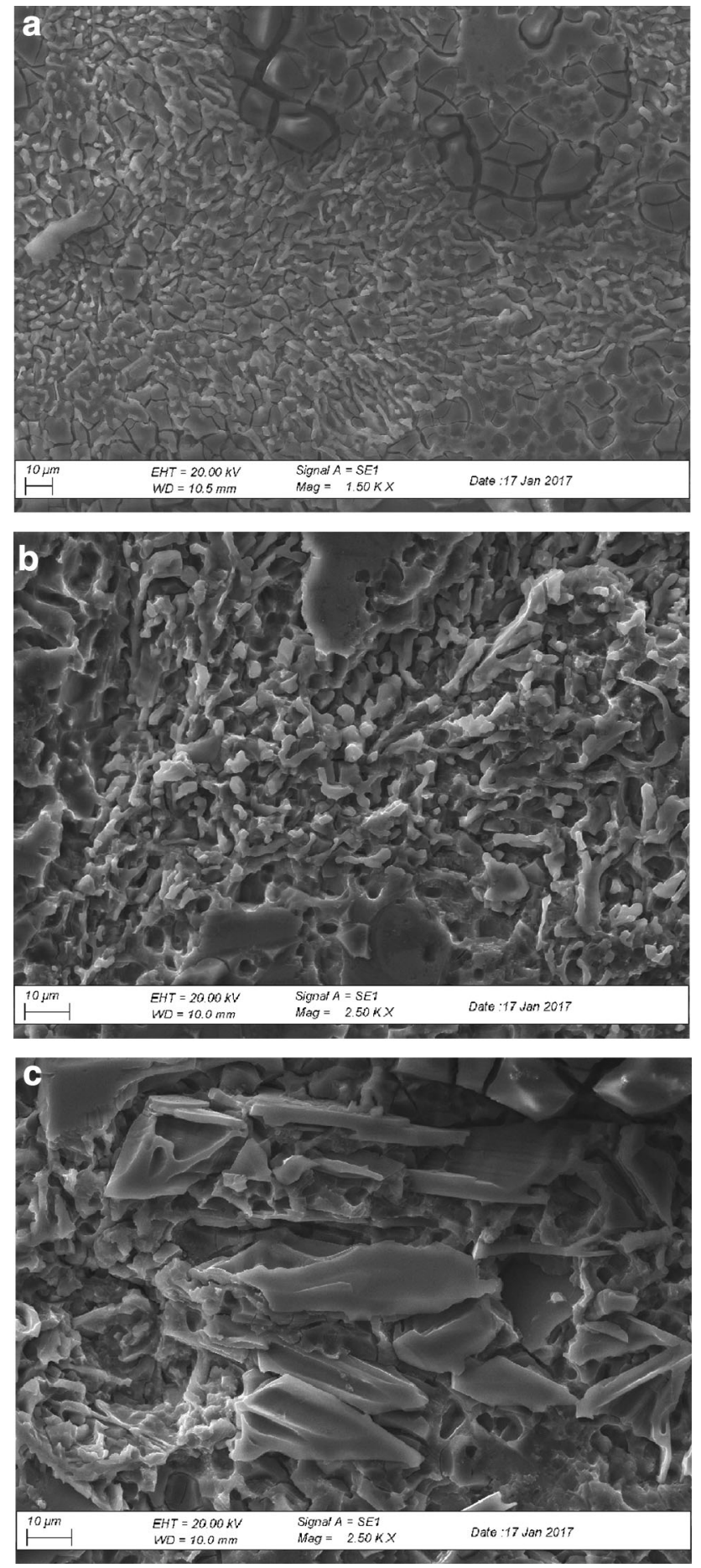

Figure 12. 3D morphology of Si particles: (a) 95 ppm Srmodified alloy, (b) coral-like Si and (c) plate-like Si in the over-modified alloy with 820 ppm of Sr.

From Figure 11b, the relevance of outliers in analysing the results emerges. As can be seen, for all the considered alloys, there are many anomalous values. As depicted in Figure $11 \mathrm{~b}$, the alloy with $820 \mathrm{ppm}$ of $\mathrm{Sr}$ shows the lowest variability in terms of both the number of outliers and their size. In addition, it should be noted that there are some other points that are possibly the result of erroneous evaluations since they are very far from the population of outliers (see extreme data of the alloys with 92, 154, 360 and $820 \mathrm{ppm}$ of $\mathrm{Sr}$ ). These results should be related to the ML values reported in Figure 10 where, irrespective of the Sr content, ML does not reach the fully modified level defined by the AFS charts.

\section{Microstructural Homogeneity}

It has been observed from the OM images of Figure 6 that addition of $\mathrm{Sr}$ over a certain amount can affect microstructural homogeneity and this aspect could be associated with the observed increase in ML, depicted in Figure 10. For the purpose of evaluating the eutectic Si particles distribution in the presence of a large amount of $\mathrm{Sr}$, detailed SEM analyses of the alloy with $820 \mathrm{ppm}$ were conducted. Morphology and distribution of Si were highlighted by using an aqueous solution of $\mathrm{HCl} 25 \%$ which dissolved only the $\alpha$-Al phase, making it possible to observe the crystalline morphology and spatial distribution of the unetched eutectic phase. Figure 12a shows the 3D coral-like morphology of the well-modified eutectic $\mathrm{Si}$ particles of the alloy with $95 \mathrm{ppm}$ of Sr. The 3D morphologies of $\mathrm{Si}$ observed by SEM on the deep etched sample containing $820 \mathrm{ppm}$ of $\mathrm{Sr}$ are reported in Figure $12 \mathrm{~b}$, c. Metallographic examinations proved that increasing $\mathrm{Sr}$ content over a certain amount affects the microstructural homogeneity, as revealed by the simultaneous presence of coral-like (Figure 12b) and plate-like (Figure 12c) eutectic Si structures.

Following these qualitative microstructural observations, quantitative evaluation of homogeneity was addressed by a numerical approach based on a detailed IA.

From Figure 10, it is worth noting that, irrespective of $\mathrm{Sr}$ content, none of the samples reaches the fully modified AFS level. It is widely accepted that TA highlights the effects of $\mathrm{Sr}$ as a modifier without, however, indicating the effect on Si particle homogeneity.

In this respect, as reported by Gruzleski and Closset ${ }^{24}$ inhomogeneously modified structures are common results of Sr-treated alloys. A quantitative way to assess the homogeneity of object distribution, Si particles in this case, is to use the Lorenz curve and the related homogeneity parameter, $H$, as proposed by Rossi et al. ${ }^{55}$ Homogeneity $H$ is computed by Eqn. 3 as:

$H_{(x)}=\frac{2}{n^{2} \bar{x}}\left(\sum_{i=1}^{n}(n+1-i) x_{i}\right)-\frac{1}{n}$

Eqn. 3

where $n$ is the number of particles in the analysed ROI, $\bar{x}$ is the arithmetic mean value of the considered parameter, and $x_{i}$ is the value of the considered parameter whose data are indexed in non-decreasing order. 


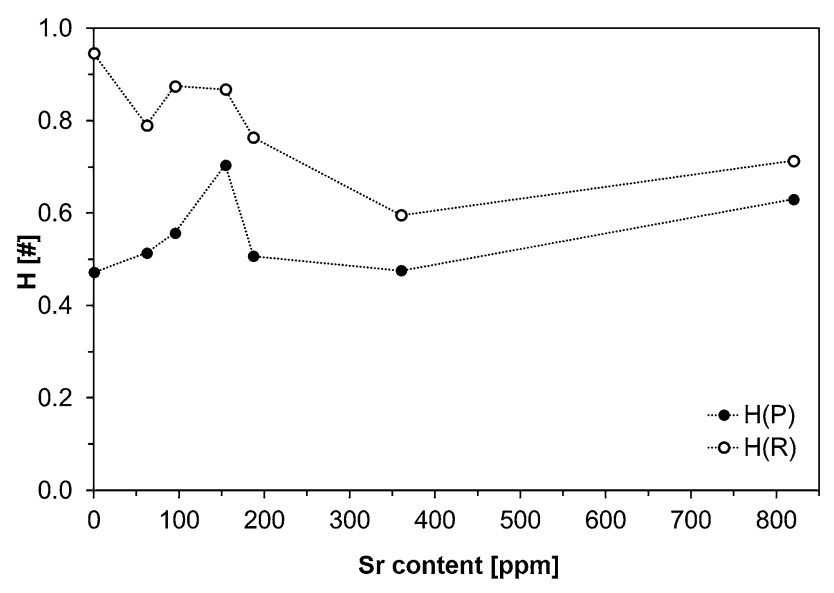

Figure 13. Evolution of homogeneity based on perimeter of Si particles, $H(P)$, and object homogeneity, $H(R)$.

It is also important to note that, to the knowledge of the authors, there are no data which make reference to the specific dimensions of ROI that should be considered during IA, and likewise, no data have been discovered, indicating a minimum threshold for the analysed Si particles. Thus, in the present study, the adopted combination of 36 ROI was considered suitable to give an accurate measurement of the actual ML values and a minimum dimension of 10 pixels for each Si particle was established as the threshold value.

Starting from these concepts, eutectic homogeneity was evaluated by considering both the distribution of Si particles among different regions of the analysed ROI and also the similarity of the particles. The distribution of Si particles is correlated to so-called region homogeneity, $H(\mathrm{R})$, computed by dividing the ROI into four regions. The number of particles detected in each region is considered as the $x$ parameter in Eqn. 3. The similarity of the particles is assessed with the so-called object homogeneity, calculated by Eqn. 3 with a specific geometrical parameter. In particular, the perimeter of the particles, analysed through image analysis software, was assumed to be a convenient $x$ parameter for Eqn. 3 and the resulting value is indicated as $H(\mathrm{P}){ }^{55}$

A comparison between the evolutions of $H(\mathrm{R})$ and $H(\mathrm{P})$, as a function of $\mathrm{Sr}$ content, is provided in Figure 13. Considering the values of $H(\mathrm{R})$ it is possible to evaluate $\mathrm{Si}$ particle distribution and consequently the homogeneity of the analysed ROI. As can be seen from Figure 13, the unmodified alloy reached the $\mathrm{H}(\mathrm{R})$ highest value revealing that unmodified Si particles are homogeneously distributed in the ROI under consideration. Small amounts of Sr lead to a decrease in region homogeneity, which is significantly reduced for higher $\mathrm{Sr}$ contents. In general, therefore, it seems that the highest region homogeneity is obtained for Sr content up to about $150 \mathrm{ppm}$, while an excess of modifiers negatively affects the distribution of the Si particles.

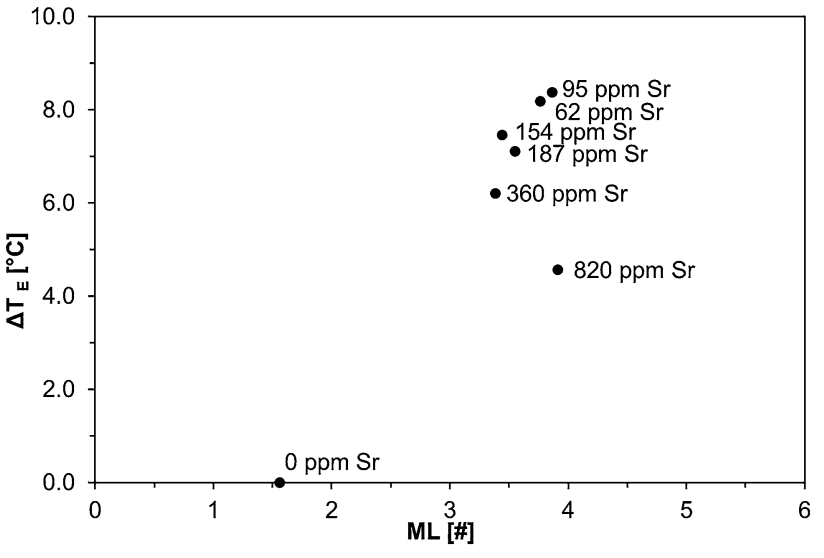

Figure 14. Eutectic undercooling as a function of the $M L$ based on the perimeter.

These findings may be related also to the $H(\mathrm{P})$ evolution, provided in Figure 13. The alloy containing $154 \mathrm{ppm}$ of $\mathrm{Sr}$ provides the highest perimeter homogeneity although in all cases the values are lower than 0.8. Evolution of $H(\mathrm{P})$, i.e. the measurement of variability in perimeter values in each ROI, suggests that the similarity of the detected particles is not significantly affected by $\mathrm{Sr}$ content. As can be seen, slight variations in perimeters for each ROI in both unmodified and modified alloys are shown and values are, on average, 0.5. Despite this, it is interesting to note that the alloy with $154 \mathrm{ppm}$ of $\mathrm{Sr}$ shows the highest value of $H(\mathrm{P})$ and therefore it can be assumed that the $\mathrm{Sr}$ amount of $154 \mathrm{ppm}$ provides the best combination in terms of object and region homogeneity.

Based on this, a possible explanation for the ML listed in Figure 10 arises from the comparison of Figures 11 and 13. It is likely that homogeneity does not influence the method proposed by Djurdjevic et al. ${ }^{22}$ since it is based on AFS charts, which in turn are limited to small regions of the microstructure where associated particle homogeneity is very high. As for the samples in the present study, partially or fully modified structures and unmodified structures can be found in the same sample and, in addition, in the same ROI. Thus, the present study provides experimental evidence with respect to the importance of Si particles distribution in ML evaluation.

These reported findings suggest that caution is necessary for interpreting the correlation between AFS levels and the results of IA in the presence of inhomogeneous distribution of Si particles.

\section{Thermal Analysis and Modification Level}

To predict ML of the melt by using TA, it is necessary to correlate microstructural evaluations with certain TA parameters, e.g. with eutectic growth undercooling. Figure 14 presents $\Delta T_{E}$ on the ordinate and $\mathrm{ML}$ on the 
abscissa, calculated according to the method proposed by Djurdjevic et al. ${ }^{22}$ using the perimeter of Si particles. As can be seen, for the unmodified sample ( $0 \mathrm{ppm}$ of $\mathrm{Sr}$ ) ML resulting from IA is the lowest and is located on the left side of the graph. Addition of $\mathrm{Sr}$ causes a marked growth of $\Delta T_{E}$ in conjunction with an increase in the associated ML. This result is consistent with data obtained in previous studies, ${ }^{1,2,22,33,58}$ indicating that ML increases as eutectic growth undercooling increases since they are both dependent on $\mathrm{Sr}$ amount. ${ }^{12}$ Due to the issues reported in "Microstructural Homogeneity" section regarding the inhomogeneity associated with the highest $\mathrm{Sr}$ content $(820 \mathrm{ppm})$, the experimental findings depicted in Figure 14 should be evaluated by considering both $\Delta T_{E}$ and the ML. The sample which contains $820 \mathrm{ppm}$ shows high ML but the lowest eutectic undercooling and cannot, therefore, be defined as properly modified. It is worth noting that the best combination of high $\Delta T_{E}$ and high ML belongs to the alloy modified with $95 \mathrm{ppm}$ of $\mathrm{Sr}$, without considering the alloy with 820 ppm of Sr. What stands out in Figure 14 is that increasing $\mathrm{Sr}$ content causes a drop in both $\Delta T_{E}$ and ML values and therefore does not improve refinement of the $\mathrm{Si}$ particles. Despite the fact that the ML values obtained by the median method mentioned in Sect. 2.3 cannot be assumed to be absolute values due to inhomogeneity issues, the reported trend of eutectic undercooling and ML provides good assessment for an adequate $\mathrm{Sr}$ amount.

\section{Conclusions}

The purpose of the current study is to understand the effects of an increasing amount of $\mathrm{Sr}$ on the modification level observed in an $\mathrm{Al}-7 \% \mathrm{Si}-0.3 \% \mathrm{Mg}$ alloy, by way of comparing the results obtained from TA and IA techniques. According to the experimental findings, the following conclusions can be drawn:

- TA curves revealed that eutectic reaction temperature of $\mathrm{Sr}$-modified alloys was lowered by up to $10^{\circ} \mathrm{C}$ with respect to the unmodified alloy. Minimum values of all the eutectic transformation temperatures are achieved when $\mathrm{Sr}$ content is around $100 \mathrm{ppm}$;

- Microstructural investigations showed up the effect of $\mathrm{Sr}$ in transforming $\mathrm{Si}$ particles from plate-like into fine fibrous ones. High $\mathrm{Sr}$ contents lead to over-modification, which was confirmed by the detection of a large number of $\mathrm{Al}_{2} \mathrm{Si}_{2} \mathrm{Sr}$ particles. EDS spectra showed the presence of $\mathrm{Ca}$ peaks in these particles, suggesting a composition of $\mathrm{Al}_{2} \mathrm{Si}_{2}(\mathrm{Sr}, \mathrm{Ca})$ due to the electronic valence configuration of $\mathrm{Sr}$ and $\mathrm{Ca}$;

- From a comparison of the methodologies proposed by Djurdjevic et al. ${ }^{22}$ and by Chen et al. ${ }^{26}$ for ML assessment, it was found that the mean perimeter of $\mathrm{Si}$ particles can be adopted as a proper indicator of ML, while $S^{*}$ parameter evolution was not consistent with $\mathrm{Sr}$ amounts in the alloys;

- Microstructural investigations coupled with statistical analyses reveal that homogeneity of the distribution of $\mathrm{Si}$ particles plays a main role in defining ML of the alloy. Taking as a starting point that all methods proposed in the literature, based on AFS charts, present as main drawback the fact that reference images are limited to small regions of the microstructure and are not always representative of real cases, the present study proposes a new numerical approach. In particular, a detailed IA carried out by numerical evaluations is needed for a quantitative evaluation of homogeneity. Therefore, ML evaluation cannot forego the homogeneity assessment. The reported results give clear evidence that $\mathrm{Sr}$ content affects the distributions of $\mathrm{Si}$ particles, in terms of both region homogeneity $H(\mathrm{R})$ and object homogeneity $H(\mathrm{P})$. It is noteworthy that the proposed approach, which combines the analyses of homogeneity and the ML assessment, enables a detailed evaluation of the goodness of the modification treatment and it is especially useful for alloys where over-modification occurs.

\section{Acknowledgements}

The authors would like to express their appreciation to the Mario Mazzucconi Foundry of Ponte San Pietro (BG) for providing research facilities. The authors are also indebted to Stefano Pirletti of Mario Mazzucconi Foundry for his invaluable assistance and technical support provided during experimental castings. Many thanks are also due to Professor Vincenzo Guidi for the contribution to statistical data analysis.

\section{REFERENCES}

1. S. Argyropoulos, B. Closset, J.E. Gruzleski, H. Oger, Trans. Am. Foundrymen's Soc. 91, 351 (1983)

2. D. Apelian, G.K. Sigworth, K.R. Whaler, AFS Trans. 92, 297 (1984)

3. S. Farahany, A. Ourdjini, M.H. Idris, J. Therm. Anal. Calorim. 109, 105 (2012)

4. S. Hegde, K.N. Prabhu, J. Mater. Sci. 43, 3009 (2008)

5. G.K. Sigworth, Int. J. Metalcast. 2, 19 (2008)

6. S.G. Shabestari, F. Shahri, J. Mater. Sci. 39, 2023 (2004)

7. A.K. Dahle, K. Nogita, S.D. McDonald, C. Dinnis, L. Lu, Mater. Sci. Eng. A 412-414, 243 (2005)

8. D. Emadi, L.V. Whiting, S. Nafisi, R. Ghomashchi, J. Therm. Anal. Calorim. 81, 235 (2005)

9. G.K. Sigworth, Inter. Metalcast. 2, 19 (2008)

10. M. Zamani, S. Seifeddine, Int. J. Metalcast. 10, 457 (2016) 
11. S. Farahany, A. Ourdjini, M.H. Idris, S.G. Shabestari, J. Therm. Anal. Calorim. 114, 705 (2013)

12. M. Malekan, S.G. Shabestari, J. Therm. Anal. Calorim. 103, 453 (2011)

13. V.A. Hosseini, S.G. Shabestari, R. Gholizadeh, Mater. Des. 50, 7 (2013)

14. S.G. Shabestari, S. Ghodrat, Mater. Sci. Eng. A 467, 150 (2007)

15. S. Gowri, F.H. Samuel, AFS Trans. 101, 611 (1993)

16. S.G. Shabestari, M. Malekan, J. Alloys Compd. 492, 134 (2010)

17. N. Tenekedjiev, J.E. Gruzleski, AFS Trans. 99, 1 (1991)

18. D. Emadi, L.V. Whiting, AFS Trans. 110, 285 (2002)

19. N. Tenekedjiev, H. Mulazimoglu, B. Closset, J. Gruzleski, Microstructures and Thermal Analysis of Strontium-Treated Aluminum-Silicon Alloys (American Foundrymen's Society, Inc., Schaumburg, 1995)

20. A.A. Canales, J. Talamantes-Silva, D. Gloria, S. Valtierra, R. Colás, Thermochim. Acta 510, 82 (2010)

21. F.C. Robles Hernández, J.H. Sokolowski, J. Alloys Compd. 419, 180 (2006)

22. M. Djurdjevic, H. Jiang, J. Sokolowski, Mater. Charact. 46, 31 (2001)

23. R. Francis, J. Sokolowski, Metalurgija 14, 3 (2008)

24. J.E. Gruzleski, B.M. Closset, The Treatment of Liquid Aluminum-Silicon Alloys (American Foundrymen's Society, Inc., Schaumburg, 1990)

25. R.I. MacKay, M. Djurdjevic, J.H. Sokolowski, W.J. Evans, AFS Trans. 108, 505 (2000)

26. X. Chen, H. Geng, Y. Li, Mater. Sci. Eng. A 419, 283 (2006)

27. S. Eguskiza, A. Niklas, A.I. Fernández-Calvo, F. Santos, M.B. Djurdjevic, Int. J. Metalcast. 9, 43 (2015)

28. H.Y. Geng, Y.X. Li, X. Chen, X. Wang, Scr. Mater. 53, 69 (2005)

29. M. Zamani, S. Seifeddine, in Light Metals, ed. by M. Hyland (Springer, Cham, 2015), pp. 955-960

30. M. Makhlouf, H. Guthy, J. Light Met. 1, 199 (2001)

31. L. Backerud, G. Chai, J. Tamminen, Solidification Characteristics of Aluminum Alloys. Foundry Alloys, vol. 2 (American Foundrymen's Society, Inc., Schaumburg, 1990)

32. A. Niklas, A. Abaunza, A.I. Fernández-Calvo, J. Lacaze, R. Suárez, Foundry 59, 1167 (2010)

33. H. Jiang, J.H. Sokolowski, M.B. Djurdjevic, W.J. Evans, AFS Trans. 23, 505 (2000)

34. R. Dasgupta, C.G. Brown, S. Marek, AFS Trans. 96, 297 (1988)
35. S. Nafisi, R. Ghomashchi, Mater. Sci. Eng. A 415, 273 (2006)

36. G.K. Sigworth, Inter. Metalcast. 2, 19 (2008)

37. M. Zamani, S. Seifeddine, Inter. Metalcast. 10, 457 (2016)

38. G.K. Sigworth, J. Campbell, J. Jorstad, Inter. Metalcast. 3, 657 (2009)

39. A.K. Dahle, K. Nogita, J.W. Zindel, S.D. McDonald, L.M. Hogan, Metall. Mater. Trans. A 32A, 949 (2001)

40. M. Djurdjevic, T. Stockwell, J. Sokolowski, Int. J. Cast Met. Res. 12, 67 (1999)

41. B. Closset, J.E. Gruzleski, Metall. Trans. A 13A, 945 (1982)

42. M. Timpel, N. Wanderka, R. Schlesiger, T. Yamamoto, N. Lazarev, D. Isheim, G. Schmitz, S. Matsumura, J. Banhart, Acta Mater. 60, 3920 (2012)

43. M. Zarif, B. Mckay, P. Schumacher, Metall. Mater. Trans. A 42, 1684 (2011)

44. F.H. Samuel, A.M. Samuel, H.W. Doty, S. Valtierra, Metall. Mater. Trans. 32A, 2061 (2001)

45. M.F. Ibrahim, S.A. Alkahtani, KhA Abuhasel, F.H. Samuel, Mater. Des. 86, 30 (2015)

46. A. Abdollahi, J.E. Gruzleski, Int. J. Cast Met. Res. 11, 145 (1998)

47. S.S. Sreeja Kumari, R.M. Pillai, B.C. Pai, J. Alloys Compd. 460, 472 (2008)

48. A.M. Samuel, H.W. Doty, S.G. Valtierra, F.H. Samuel, Mater. 9, 126 (2016)

49. S.S. Sreeja Kumari, R.M. Pillai, B.C. Pai, Int. Mater. Rev. 50, 216 (2005)

50. S. El-Hadad, A.M. Samuel, F.H. Samuel, H.W. Doty, S. Valtierra, Int. J. Cast Met. Res. 15, 551 (2003)

51. B. Lorenz, J. Cmaidalka, R.L. Meng, J.J. Xue, C.W. Chu, Physics C 408-410, 171 (2004)

52. M.J. Zhang, X.H. Cui, G.R. Gu, B.J. Wu, L.H. Tian, Comput. Mater. Sci. 92, 439 (2014)

53. S. Wenner, C.D. Marioara, S.J. Andersen, R. Holmestad, Mater. Sci. Eng. A 575, 241 (2013)

54. R. Bjorge, C.D. Marioara, S.J. Andersen, R. Holmestad, Metall. Mater. Trans. A 41, 1907 (2010)

55. P. Rossi, M. Engstler, F. Mücklich, Pract. Metall. 52, 571 (2015)

56. J.W. Tukey, Exploratory Data Analysis (AddisonWesley, Reading, 1977)

57. J.E.V. Ferreira, M.T.S. Pinheiro, W.R.S. dos Santos, R. da Silva Maia, Educ. Quim. 27, 209 (2016)

58. S. Gowri, AFS Trans. 29, 503 (1994) 